\title{
Urban Aerosols Induce Pro-inflammatory Cytokine Production in Macrophages and Cause Airway Inflammation in Vivo
}

\author{
Tokuyuki Yoshida, ${ }^{a, b, \#}$ Yasuo YoshiokA,${ }^{a, b, c, \#}$ Maho Fujimura, ${ }^{a, b}$ Hiroyuki Kayamuro, ${ }^{a, b}$ \\ Kohei Yamashita, ${ }^{a, b}$ Kazuma Higashisaka, ${ }^{a, b}$ Ryosuke NaKanishi, ${ }^{a, b}$ Yuki Morishita, ${ }^{a, b}$ \\ Hiromi NABESHI ${ }^{a, b}$ Takuya Yamashita,${ }^{\mathrm{a}, \mathrm{b}}$ Masashi MuroI,${ }^{d}$ Kenichi Tanamoto, ${ }^{d}$ \\ Kazuya Nagano, ${ }^{b}$ Yasuhiro ABE, ${ }^{b}$ Haruhiko Kamada, ${ }^{b, c}$ Yuichi KanaI, ${ }^{e}$ Tadanori Mayumi, ${ }^{e}$ \\ Norio Itoh, ${ }^{a}$ Tomoaki Yoshikawa, ${ }^{a, b}$ Shinichi TsunodA, ${ }^{*, b, c}$ and Yasuo Tsutsumi ${ }^{*, a, b, c}$ \\ ${ }^{a}$ Department of Toxicology and Safety Science, Graduate School of Pharmaceutical Sciences, Osaka University; ${ }^{c}$ The \\ Center for Advanced Medical Engineering and Informatics, Osaka University; 1-6 Yamadaoka, Suita, Osaka 565-0871, \\ Japan: ${ }^{b}$ Laboratory of Pharmaceutical Proteomics, National Institute of Biomedical Innovation (NiBio); 7-6-8 Saito- \\ asagi, Ibaraki, Osaka 567-0085, Japan: ${ }^{d}$ Research Institute of Pharmaceutical Sciences, Musashino University; 1-1-20 \\ Shinmachi, Nishitokyo, Tokyo 202-8585, Japan: and ${ }^{e}$ Graduate School of Pharmaceutical Sciences, Kobe-Gakuin \\ University; 1-1-3 Minatojima, Chuo-ku, Kobe 650-8586, Japan.
}

Received January 7, 2010; accepted February 16, 2010; published online February 26, 2010

Urban air pollution, especially in developing countries, is a crucial environmental problem. Urban aerosols may contain various kinds of substances and induce harmful effects such as allergic diseases. Therefore, it is critical to clarify the biological effects of urban aerosols on human health. In this study, we evaluated the induction of airway inflammation in vitro and in vivo due to exposure of urban aerosols. We investigated cytokine production and nuclear factor- $\kappa B(N F-\kappa B)$ activation after stimulation of macrophage cells by exposure of urban aerosols. Urban aerosols were found to induce the production of interleukin (IL)-8, tumor necrosis factor- $\alpha$ and IL-1 $\beta$ on macrophage cells. In addition, we showed that NF- $\kappa$ B pathway regulated the urban aerosols-induced inflammatory cytokine response. Moreover, the intranasal administration of urban aerosols resulted in increases in the total cell number in bronchoalveolar lavage and infiltration of eosinophils in lung tissue. These results indicate that urban aerosols induce respiratory inflammation and onset of inflammatory disease due to an activation of the immune system.

Key words inflammation; urban aerosol; bronchoalveolar lavage; inflammatory cytokine; nuclear factor- $\kappa \mathrm{B}$

Urban air pollution is a crucial environmental problem in industrialized and developing countries. ${ }^{1-3)}$ Increased levels of air pollution have been associated with a wide range of health effects. ${ }^{4)}$ Many of these effects involve altered inflammatory responses in the respiratory system and cardiopulmonary disease. ${ }^{5,6)}$ Urban aerosols comprise a mixture of hundreds of organic and inorganic compounds in both gas and particle phases. ${ }^{7-9)}$ Epidemiological studies have suggested that increased levels of particulate matter (PM) in ambient air are associated with adverse effects in the respiratory as well as cardiovascular system. ${ }^{10-12)}$ In fact, respiratoryassociated morbidity and mortality, such as increased cardiopulmonary mortality and exacerbation of asthma, were observed after days of exposure to elevated PM air pollution. ${ }^{13,14)}$

Pulmonary inflammation is one potentially important type of response to inhalation of urban aerosols. ${ }^{12,14)}$ This response induces exacerbation of asthma and chronic obstructive pulmonary disease. Urban aerosols invade pulmonary tissue where they interact with macrophages and epithelial cells as a first line of lung defense. Macrophage is an especially important target for urban aerosols in the lung, as it is responsible for the clearance of inhaled particles via phagocytosis and for stimulation of allergic inflammation and airway remodeling. ${ }^{15,16)}$ Although macrophages are known to respond to inhaled particulates, the effects of inhaled particulates on the function of these cells are not well defined.

In this study, to complement the array of epidemiological findings, we focus specifically on the inflammatory effects of urban aerosols on macrophages in vitro and on the induced exacerbation of lung inflammation following acute exposure to urban aerosols in vivo.

\section{MATERIALS AND METHODS}

Characteristics of Urban Aerosols The urban aerosols from Beijing, China, were purchased from the National Institutes for Environmental Studies, Japan. The particles used in this study were suspended in distilled water and their sizes measured using Zetasizer Nano-ZS (Malvern Instrument Ltd., Malveran, U.K.). More than $99 \%$ of urban aerosols had a particle size $\leq 1 \mu \mathrm{m}$. The endotoxin level was quantified by a Limulus amebocyte lysate assay (QCL-1000; Bio Whittaker, Walkersville, MD, U.S.A.). The endotoxin content of the urban aerosols was $\leq 1250 \mathrm{pg} / \mathrm{mg}$ aerosol.

Cell Culture and Mice Human monocyte-like cell line THP-1 was obtained from the American Type Culture Collection (Manassas, VA, U.S.A.). THP-1 cells were grown in RPMI 1640 (Wako Pure Chemical Industries, Osaka, Japan), supplemented with $10 \%$ heat-inactivated fetal bovine serum (FBS), $0.05 \mathrm{~mm} 2$-mercaptoethanol and $1 \%$ antibiotic mixture (penicillin 10000 units $/ \mathrm{ml}$, streptomycin $10 \mathrm{mg} / \mathrm{ml}$, and amphotericin B $25 \mu \mathrm{g} / \mathrm{ml}$ ) (Nacalai Tesque, Kyoto, Japan). RAW-ELAM cells, which constitutively express luciferase reporter gene regulated with nuclear factor- $\kappa \mathrm{B}(\mathrm{NF}-\kappa \mathrm{B})$ in RAW264 parental cells, were grown in Dulbecco's modified Eagle medium (Wako Pure Chemical Industries), supplemented with $10 \%$ heat-inactivated FBS supplemented with $0.5 \mathrm{mg} / \mathrm{ml}$ geneticin (G418; Wako Pure Chemical Industries). Female BALB/c mice were purchased from Nippon SLC 
(Hamamatsu, Japan) and used at 6 to 8 weeks of age. All of the animal experimental procedures in this study were performed in accordance with the National Institute of Biomedical Innovation guidelines for the welfare of animals.

Macrophage Differentiation To induce macrophage differentiation of THP- 1 cells, cells $\left(1 \times 10^{4} /\right.$ well $)$ were plated in 96-well plates, added with $100 \mathrm{ng} / \mathrm{ml}$ of phorbol myristate acetate plus $100 \mathrm{~nm}$ 1,25-dihydroxy vitamin D3 (Wako Pure Chemical Industries) and incubated for $24 \mathrm{~h}$.

Measurement of Cytokine Production Macrophagelike THP-1 cells $\left(1 \times 10^{5} /\right.$ well $)$ were plated in 96 -well plates and on the following day stimulated for $24 \mathrm{~h}$ with either $100 \mathrm{ng} / \mathrm{ml}$ lipopolysaccharide (LPS) or $0.64-80 \mu \mathrm{g} / \mathrm{ml}$ urban aerosols. Pro-inflammatory cytokines, interleukin (IL)$1 \beta$ and IL- 8 , were measured in the culture supernatant by ELISA according to the manufacturer's instructions (BD Bioscience, San Diego, CA, U.S.A.). Tumor necrosis factor (TNF)- $\alpha$ was measured using biotinylated anti-human TNF polyclonal antibody (R\&D, Minneapolis, MN, U.S.A.) as previously described. ${ }^{17)}$

NF- $\boldsymbol{\kappa}$ B Assay The NF- $\kappa$ B-dependent luciferase reporter assay was performed as described previously. ${ }^{18)}$ RAW-ELAM cells $\left(2 \times 10^{5} /\right.$ well $)$ were plated in 12 -well plates and on the following day stimulated for $6 \mathrm{~h}$ with either $100 \mathrm{ng} / \mathrm{ml} \mathrm{LPS}$ or various concentration of urban aerosols. The NF- $\kappa \mathrm{B}$ reporter gene activity was measured according to the manufacturer's instructions (Promega, Madison, WI, U.S.A.). The protein concentrations of the cellular extracts were determined by the Bradford method (Bio-Rad, Hercules, CA, U.S.A.), and the reporter gene activity was normalized to the protein concentration for the compensation of difference in cell numbers and viabilities between wells.

Evaluation of Inflammatory Responses in Vivo Each mouse was anesthetized by pentobarbital (Dainippon Pharmaceutical Co., Osaka, Japan), and intranasally (i.n.) exposed to $4-400 \mu \mathrm{g}$ urban aerosols diluted in $50 \mu \mathrm{l}$ sterile phosphate-buffered saline (PBS); control mice received LPS or PBS. After $24 \mathrm{~h}$, mice were sacrificed and then samples (bronchoalveolar lavage (BAL) fluids and lung tissue) were collected. The total BAL cell number was counted with a NucleoCounter (Chemometec, Osaka, Japan). For histological examination, the right lung was fixed with $10 \%$ neutral buffered formalin and stored for $24 \mathrm{~h}$. Lung samples were then embedded in paraffin and cut into $5-\mu \mathrm{m}$ thick sections. The sections were mounted on slides and stained with hematoxylin and eosin to examine the amount of lung inflammation under light microscopy. For examining eosinophils, the slides were stained using the Luna method. That is, the slides were stained in a working $1 \%$ Biebrich scarlet solution, dipped in lithium carbonate solution, and washed in running water, followed by counterstaining in a working hematoxylin solution, further washed in running water, and dehydrated.

Statistical Analysis All results are expressed as means S.E.M. or S.D. Differences were compared using Bonferroni's method after analysis of variance (ANOVA).

\section{RESULTS AND DISCUSSION}

Urban air pollution is a crucial environmental problem, especially in developing countries. As urban aerosols may contain various kinds of harmful substances, they are likely risk factors for conditions such as allergic diseases or cancer. ${ }^{10,12,19)}$ Clarification of the immunotoxic effects caused by urban aerosols is therefore important. In this study, we examined the potential of urban aerosols to induce inflammation and evaluated the risk associated with allergic diseases.

Cytokine secretion by activated macrophages contributes to inflammation in the lung. ${ }^{20)}$ Therefore, to examine the effect of urban aerosols on macrophages, we investigated cytokine production after stimulation of macrophage-like THP1 cells by exposure of $0.64-80 \mu \mathrm{g} / \mathrm{ml}$ urban aerosols for $24 \mathrm{~h}$. Urban aerosols were found to induce the production of IL- 8 , TNF- $\alpha$ and IL- $1 \beta$ on THP- 1 cells (Figs. 1A-C). Such pro-inflammatory cytokines may initiate and exacerbate inflammation. IL- $1 \beta$ is particular important cytokine since it is a potent inflammatory mediator, stimulating chemokine production, recruiting leukocytes to the site of injury, and inducing the synthesis of TNF. ${ }^{21,22)}$ IL- 8 is a neutrophil attractor, and an influx of neutrophil may lead to a sustained inflammation and possibly tissue damage. ${ }^{23,24)}$ Therefore, urban aerosols appear to induce pulmonary inflammation by activating macrophages. To verify the signaling pathway of cytokine production on macrophages, we examined the activity of NF- $\kappa \mathrm{B}$ induced by urban aerosols. As NF- $\kappa \mathrm{B}$ is one of the major transcription factors which regulate the expression of many cytokine genes, ${ }^{25)}$ including IL-1 $\beta$, IL-8, and TNF-
A

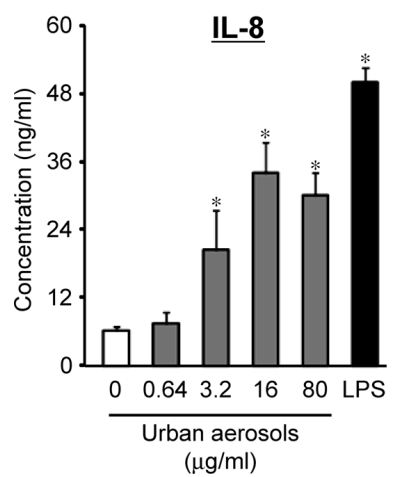

B

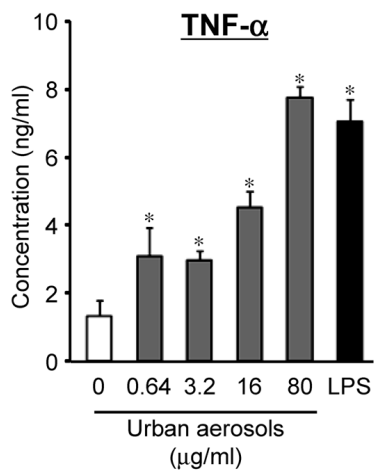

C

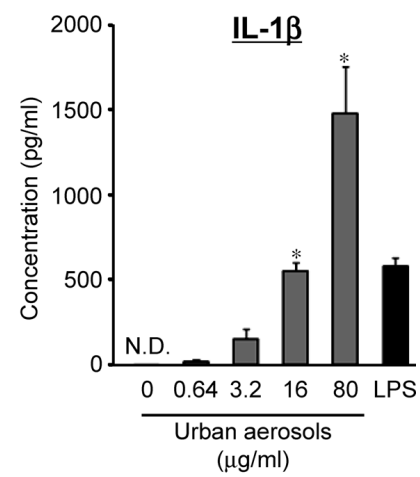

Fig. 1. Cytokine Production in Macrophage-Like THP-1 Cells upon Urban Aerosol Exposure

THP-1 cells were incubated with $0.8-80 \mu \mathrm{g} / \mathrm{ml}$ urban aerosols or $100 \mathrm{ng} / \mathrm{ml}$ LPS for $24 \mathrm{~h}$. IL- 8 (A), TNF- $\alpha$ (B), and IL-1 $\beta$ (C) levels in the culture supernatants were determined by ELISA. Data represent means \pm S.D. $(* p<0.05$ compared with control group by ANOVA). 
$\alpha$, we measured its activity after exposing several dilutions of urban aerosols to RAW-ELAM. ${ }^{18)}$ An increase in the NF$\kappa \mathrm{B}$ activity was observed following urban aerosols exposure in a dose-dependent manner (Fig. 2), suggesting that the NF$\kappa \mathrm{B}$ pathway regulated the urban aerosols-induced inflammatory cytokine response.

To investigate the inflammatory responses of urban aerosols in vivo, we examined the subacute inflammatory responses of urban aerosols in lungs of mice. We exposed mice to urban aerosols ( $4-400 \mu \mathrm{g} / \mathrm{mouse} / \mathrm{d}$ ). After $24 \mathrm{~h}$ exposure, the total BAL cell number was increased dose dependently with urban aerosols, indicating that urban aerosols induce severe inflammation in the lung. In particular, $400 \mu \mathrm{g}$ urban aerosols-exposed mice exhibited sever lung inflammatory responses as similar as LPS-treated mice (Fig. 3). Furthermore on histopathological examination, lungs of $400 \mu \mathrm{g}$ urban aerosols-exposed mice expressed heavy inflammatory and degenerative processes with abundant granulocytes and tissue exudates filling in the alveolar lumina (Fig. 4A). Importantly, in the exposed lungs, urban aerosols were finely dis-

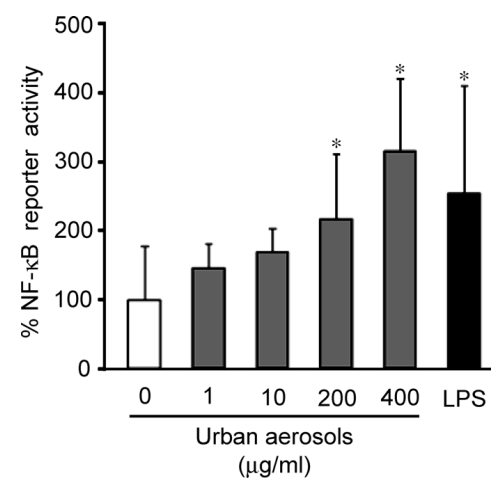

Fig. 2. Urban Aerosol-Induced NF- $\kappa$ B Activity in RAW-ELAM Cells

RAW-ELAM cells were incubated with various concentration of urban aerosols or $100 \mathrm{ng} / \mathrm{ml}$ LPS for $6 \mathrm{~h}$. The activity of NF- $\kappa \mathrm{B}$ in RAW-ELAM cells was measured by luciferase assay after treatment with increasing amounts of urban aerosols. Data represent means \pm S.D. $(* p<0.05$ compared with control group by ANOVA). persed in alveolar spaces. Among the infiltrating leukocytes, eosinophils were dramatically increased in number in the urban aerosols-exposed lungs (Fig. 4B), indicating that urban aerosols augmented the number of eosinophils and led to the subacute exacerbation of lung inflammation in mice. Eotaxin is well known eosinophil-recruiting chemokine and may be important in the development of allergic asthma. ${ }^{26)}$ However, we did not observe the production of eotaxin after stimulation of THP-1 cells by exposure of urban aerosols. It has been known that not only macrophage but also bronchial and lung epithelial cells produce the eotaxin after inflammatory stimulus. ${ }^{27)}$ Therefore we consider that urban aerosols might induce the production of eotaxin on epithelial cells in lung and recruitment of eosinophils in lung.

As in Beijing, the concentration of urban aerosols is estimated to be about $150 \mu \mathrm{g} / \mathrm{m}^{3}$, and assuming a daily respiratory volume of $15 \mathrm{~m}^{3}$ for an adult, the Beijing population is predicted to be exposed to $2250 \mu \mathrm{g}$ urban aerosols per day. ${ }^{28)}$ Based on this estimated level of human adult exposure, about

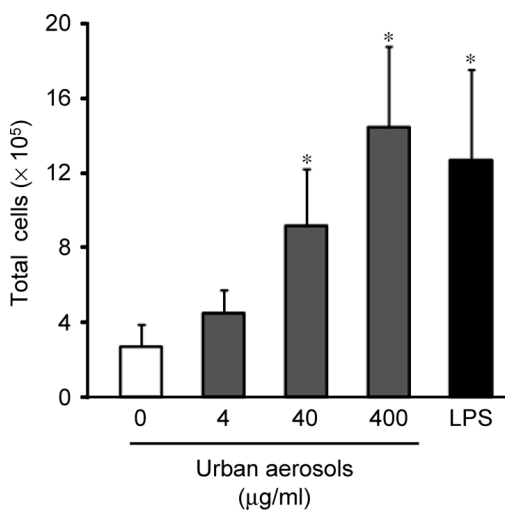

Fig. 3. Cell Recruitment in the Airways after Urban Aerosol Exposure

BALB/c mice were administered $4-400 \mu \mathrm{g}$ urban aerosols and $1 \mathrm{ng}$ LPS. After $24 \mathrm{~h}$, the total cell number was counted in the BAL fluids of mice administered with either urban aerosols or LPS. Data represent means \pm S.E.M. ( $* p<0.05$ compared with control group by ANOVA).

\section{PBS}

A

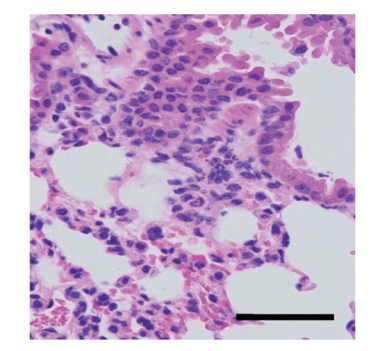

B

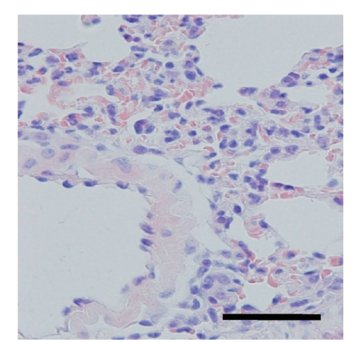

Urban aerosols

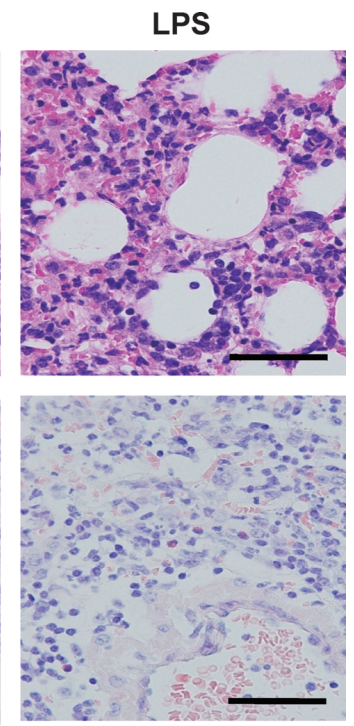

Fig. 4. Histopathological Analysis of Lung Tissue Treated with Urban Aerosols

BALB/c mice were administered with $400 \mu \mathrm{g}$ urban aerosols and $1 \mathrm{ng}$ LPS. After $24 \mathrm{~h}$, the lung tissue sections were prepared and stained with hematoxylin and eosin to assess the degree of local inflammation (A) and stained with Luna stain to determine the localization of eosinophils (B). 
$1 \mu \mathrm{g} /$ mouse is equivalent dose. Thus, it is estimated that the dosage of the urban aerosol in vivo in the present study is 4- 400 fold higher. However, we believe that they are within the physiological ranges, because the urban aerosols might be cumulatively accumulated and hardly metabolized in the body.

Our current research involves characterizing and purifying bioactive components from urban aerosols to identify their toxic components, for further elucidation of the host defense mechanism following urban aerosols exposure. Recent studies have already shown that crystalline silica, also known as an environmental pollutant, disturbs the host immune systems by activating the cytoplasmic receptor NALP3. ${ }^{29,30)}$ However, the mechanism of urban aerosols-activating host immunity is still unclear. Future analysis is therefore necessary to clarify this mechanism.

In 2006, World Health Organization designated environmental standards for PM 2.5 to be $10 \mu \mathrm{g} / \mathrm{m}^{3}$ and $35 \mu \mathrm{g} / \mathrm{m}^{3}$ for the annual and daily concentrations, respectively; while those in the United States were $10 \mu \mathrm{g} / \mathrm{m}^{3}$ and $25 \mu \mathrm{g} / \mathrm{m}^{3}$, respectively. As Beijing has one of the highest urban aerosols concentrations (around $150 \mu \mathrm{g} / \mathrm{m}^{3}$ ), our results indicated that in urban areas with severe air pollution, the population is at a high risk of inducing inflammatory cytokines and developing pulmonary diseases such as asthma.

In conclusion, our results show that urban aerosols induce pro-inflammatory cytokine production via the NF- $\kappa \mathrm{B}$ signal pathway in macrophages. Such airway exposure to urban aerosol can elicit lung inflammation in mice.

Acknowledgements This study was supported in part by Grants-in-Aid for Scientific Research from the Ministry of Education, Culture, Sports, Science and Technology of Japan, and from the Japan Society for the Promotion of Science (JSPS). This study was also supported in part by Health Labour Sciences Research Grants from the Ministry of Health, Labor and Welfare of Japan; by Health Sciences Research Grants for Research on Publicly Essential Drugs and Medical Devices from the Japan Health Sciences Foundation; by a Grant from Minister of the Environment; and by The Nagai Foundation Tokyo.

\section{REFERENCES}

1) Sandstrom T., Cassee F. R., Salonen R., Dybing E., Toxicol. Appl. Pharmacol., 207, 261-268 (2005).

2) Nautiyal J. 3rd, Garg M. L., Kumar M. S., Khan A. A., Thakur J. S., Kumar R., Int. J. Environ. Res. Public Health, 4, 268-282 (2007).

3) Dockery D. W., Ann. Epidemiol., 19, 257-263 (2009).
4) Hoek G., Brunekreef B., Goldbohm S., Fischer P., van den Brandt P. A., Lancet, 360, 1203-1209 (2002).

5) D'Amato G., Liccardi G., D'Amato M., Cazzola M., Eur. Respir. J., 20, 763-776 (2002).

6) Eggleston P. A., Chest, 132, 782S-788S (2007).

7) Saldiva P. H., Clarke R. W., Coull B. A., Stearns R. C., Lawrence J., Murthy G. G., Diaz E., Koutrakis P., Suh H., Tsuda A., Godleski J. J., Am. J. Respir. Crit. Care Med., 165, 1610-1617 (2002).

8) Bencs L., Ravindra K., de Hoog J., Rasoazanany E. O., Deutsch F., Bleux N., Berghmans P., Roekens E., Krata A., Van Grieken R., J. Environ. Monit., 10, 1148-1157 (2008).

9) Polichetti G., Cocco S., Spinali A., Trimarco V., Nunziata A., Toxicology, 261, 1-8 (2009).

10) Brunekreef B., Forsberg B., Eur. Respir. J., 26, $309-318$ (2005).

11) Bai N., Khazaei M., van Eeden S. F., Laher I., Pharmacol. Ther., 113, $16-29$ (2007).

12) O’Connor G. T., Neas L., Vaughn B., Kattan M., Mitchell H., Crain E. F., Evans R. 3rd., Gruchalla R., Morgan W., Stout J., Adams G. K., Lippmann M., J. Allergy Clin. Immunol., 121, 1133-1139 e1131 (2008).

13) Pope C. A. 3rd, Circulation, 119, 3050-3052 (2009).

14) Alessandrini F., Beck-Speier I., Krappmann D., Weichenmeier I., Takenaka S., Karg E., Kloo B., Schulz H., Jakob T., Mempel M., Behrendt H., Am. J. Respir. Crit. Care Med., 179, 984-991 (2009).

15) Becker S., Mundandhara S., Devlin R. B., Madden M., Toxicol. Appl. Pharmacol., 207, 269-275 (2005).

16) Bergamaschi E., Bussolati O., Magrini A., Bottini M., Migliore L., Bellucci S., Iavicoli I., Bergamaschi A., Int. J. Immunopathol. Pharmacol., 19, 3-10 (2006).

17) Shibata H., Kamada H., Kobayashi-Nishibata K., Yoshioka Y., Nishibata T., Abe Y., Nomura T., Nabeshi H., Minowa K., Mukai Y., Nakagawa S., Mayumi T., Tsunoda S., Tsutsumi Y., Biochim. Biophys. Acta, 1774, 1029-1035 (2007).

18) Shimomura-Shimizu M., Sugiyama K., Muroi M., Tanamoto K., Biochem. Biophys. Res. Commun., 332, 793 -799 (2005).

19) Baccarelli A., Wright R. O., Bollati V., Tarantini L., Litonjua A. A., Suh H. H., Zanobetti A., Sparrow D., Vokonas P. S., Schwartz J., Am. J. Respir. Crit. Care Med., 179, 572-578 (2009).

20) Ishii H., Fujii T., Hogg J. C., Hayashi S., Mukae H., Vincent R., van Eeden S. F., Am. J. Physiol. Lung Cell. Mol. Physiol., 287, L176L183 (2004).

21) Dinarello C. A., Chest, 118, 503-508 (2000).

22) Dinarello C. A., Annu. Rev. Immunol., 27, 519—550 (2009).

23) Nielsen A. R., Pedersen B. K., Appl. Physiol. Nutr. Metab., 32, 833 839 (2007).

24) Kobayashi Y., Front. Biosci., 13, 2400-2407 (2008).

25) Kulms D., Schwarz T., Vitam. Horm., 74, 283-300 (2006).

26) Bisset L. R., Schmid-Grendelmeier P., Curr. Opin. Pulm. Med., 11, 35-42 (2005).

27) Takizawa H., Curr. Drug Targets Inflamm. Allergy, 4, 305-311 (2005).

28) Guo Y., Jia Y., Pan X., Liu L., Wichmann H. E., Sci. Total Environ., 407, 4826-4830 (2009).

29) Hornung V., Bauernfeind F., Halle A., Samstad E. O., Kono H., Rock K. L., Fitzgerald K. A., Latz E., Nat. Immunol., 9, 847-856 (2008).

30) Cassel S. L., Eisenbarth S. C., Iyer S. S., Sadler J. J., Colegio O. R., Tephly L. A., Carter A. B., Rothman P. B., Flavell R. A., Sutterwala F. S., Proc. Natl. Acad. Sci. U.S.A., 105, 9035-9040 (2008). 